\title{
5,13-DIETHYL-10-METHYL-8-HEPTADECANONE: A COMPONENT OF POST-1976 KELEX 100
}

\section{Hans-Günter StRIEgel and Wolfgang Wiegrebe}

Institute of Pharmacy, University, P.O. Box 397, D-8400 Regensburg, F.R.G.

Received November 27, 1990

Accepted February 15, 1991

Dedicated with warm regards to Professor E. Mutschler on the occasion of his 60th birthday.

The title compound was prepared by mixed aldol condensation of 2-ethylhexanal and acetone, double bond hydrogenation, aldol autocondensation of the resulting saturated ketone and final double bond hydrogenation. It is identical with the ketone $\mathrm{C}_{22} \mathrm{H}_{44} \mathrm{O}$ previously isolated from new Kelex 100 which was erroneously assigned a furoquinoline structure.

Kelex 100 is a commercial chelating solvent extraction reagent (Ashland Oil Inc.) Sherex Chemical Co. Dublin, Ohio, U.S.A.). It was shown ${ }^{1}$ that Kelex 100 consisted of approximately $77 \cdot 7 \%$ of 7 -(1-ethenyl-3,3,5,5-tetramethylhexyl)-8-quinolinol (I) and $3.7 \%$ of 8 -quinolinol while the remainder was an unknown viscous fluorescent material. This Kelex 100 was prepared by Claisen rearrangement of the allylic ether of 8-quinolinol ${ }^{2}$.<smiles>C=CC(CC(C)(C)CC(C)(C)C)c1ccc2cccnc2c1O</smiles>

1<smiles>CCc1coc2c1ccc1cccnc12</smiles>

IV<smiles>CCCCC(CC)CCC(C)c1ccc2cccnc2c1O</smiles>

II<smiles>CCCCC(CC)CCC(=O)CC(C)CCC(CC)CCCC</smiles>

$\checkmark$

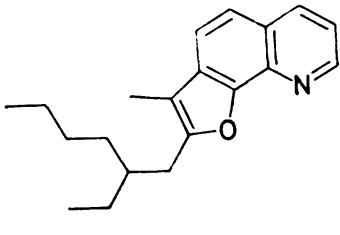

III

Since 1976 so called post-1976 Kelex 100 has contained again mainly alkenylCollect. Czech. Chem. Commun. (Vol. 56) (1991) 
quinolinols, which are, however, prepared ${ }^{3}$ by base-catalyzed addition of 8-quinolinol to branched aliphatic aldehydes (e.g. 2-ethylhexanal) and ketones (e.g. 5-ethyl-2-nonanone VII in Scheme 2). Finally, in 1982 the stability of the mixture was improved by hydrogenation ${ }^{4}$.

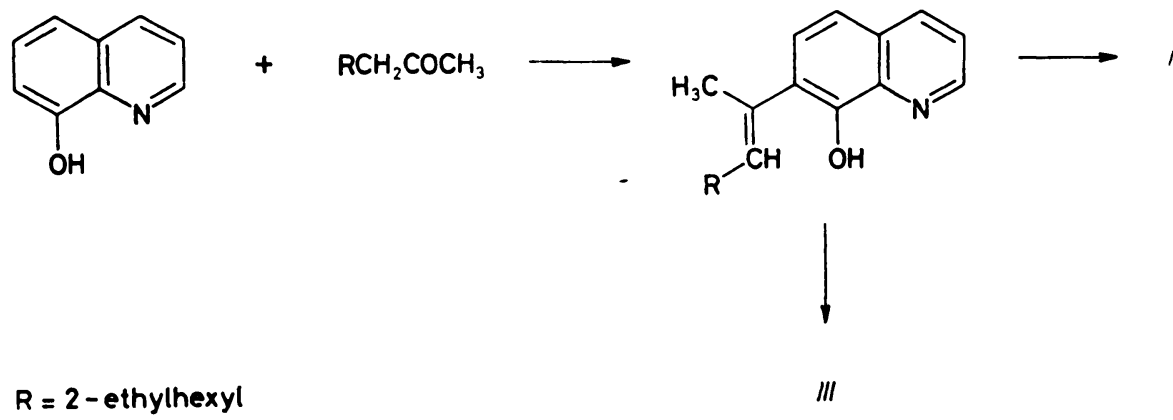

\section{SCHEME 1}

Concerning the composition of the new Kelex 100 our investigations largely confirm the published results ${ }^{5}$ : 7-(4-ethyl-1-methyloctyl)-8-quinolinol (II) is the main component, furoquinoline III being a further component (III may be formed ac-<smiles>CCCCC(C=O)CCC(C)C</smiles><smiles>CCCCCC(CC)CC=C(C)CC(=O)CC(CC)CCC(=O)CCC(CC)CCCC</smilesVIII IX SCHEME 2 
cording to Scheme 1). A third, minority component (8 wt. \%) was regarded to be another furoquinoline.

The composition of post-1976 Kelex 100 was studied ${ }^{5}$ by GC-MS and FT-IR spectrometry. Unfortunately, there are no NMR data and no fragmentation patterns quoted in this publication. The strong signal near $1700 \mathrm{~cm}^{-1}$ in the IR spectrum of a purified sample of Kelex 100 was omitted by the authors, they attributed peak No. 2 in their GC-MS diagram (TIC mode) and the corresponding ion at $m / z 197$ to structure $I V$. However, structure $I V$ for the minority component seems to be unlikely. This substance could arise in analogy to $I I I$ by addition of butanone to 8-quinolinol (Scheme 1), but the main hydrogenation product of this process was not detected. In our opinion, $I V$ cannot be obtained by the process described in literature $^{3}$. More recent GC-MS results ${ }^{6}$ revealed a branched ketone $\mathrm{C}_{22} \mathrm{H}_{44} \mathrm{O}$ to be an impurity in post-1976 Kelex 100 . It seemed to be a "dimer" of the ketone employed $^{3,4,7,8}$ in the synthesis of Kelex, $\mathrm{C}_{11} \mathrm{H}_{22} \mathrm{O}$.

Here we describe preparation and spectral properties of ketone $V(5,13-$ diethyl-10-methylheptadecan-8-one) whose mass spectrum is identical with that of the ketone $\mathrm{C}_{22} \mathrm{H}_{44} \mathrm{O}$ found in Kelex ${ }^{6}$. Moreover, the structure of $V$ explains the MS signal ${ }^{5}$ at $m / z 197$ which is not a molecular ion of compound $I V$ but a fragment ion of $V$ resulting from its $x$-cleavage. Finally, the presence of $V$ in Kelex 100 can easily be explained by self-condensation of 5-ethyl-2-nonanone (VII) leading to the unsaturated ketone VIII and its subsequent hydrogenation ${ }^{4}$. In fact, we prepared ketone $V$ in that way (Scheme 2).

The dimerisation of ketone VII to the unsaturated ketone VIII is strongly dependent on the reaction conditions. Mostly, ketones are heated to reflux in a Soxhlet or Thielepape apparatus in the presence of basic catalysts such as $\mathrm{Ba}(\mathrm{OH})_{2} .8 \mathrm{H}_{2} \mathrm{O}$, anion exchange resins and $\mathrm{Al}_{2} \mathrm{O}_{3}$. With the exception of $\mathrm{Al}_{2} \mathrm{O}_{3}$ (ref. ${ }^{9}$ ) all the reagents mentioned above proved to be unfavourable for our problem. $Z$ - and $E$-isomers of VIII could be separated from isomeric $\beta, \gamma$-unsaturated ketones (IX) by column chromatography.

However, the crude mixture of VIII and $I X$ was used for hydrogenation. Although the crude hydrogenation product did not contain any more VIII (TLC), it appeared again after distillation of crude $V$ owing to the presence of the corresponding aldol in the product. This can be overcome by a new hydrogenation and distillation. Product $V$ so obtained contains $1-2 \%$ of impurities (GC). Its IR, ${ }^{1} \mathrm{H}$ NMR, and MS data are in accordance with the suggested structure, there are no hints for diastereomers.

\section{EXPERIMENTAL}

EI-MS: Varian MAT CH5 $(70 / 12 \mathrm{eV}) .{ }^{1} \mathrm{H}$ NMR: Varian EM $390\left(90 \mathrm{MHz}, 26^{\circ} \mathrm{C}\right)$ and Bruker Spectrospin (250 MHz). IR: Nicolet $510 \mathrm{FT}$-IR, data acquisition by Mac II ci (Apple Mac- 
intosh). UV: Uvikon 810 (Kontron). TLC: $\mathrm{CH}_{2} \mathrm{Cl}_{2}$ or benzene-hexane $(1: 1)$ on $\mathrm{SiO}_{2}($ Merck 5554), detection: 2,4-dinitrophenylhydrazine $0 \cdot 2 \%$ in ethanolic $\mathrm{HCl}$, then $\mathrm{K}_{3}\left[\mathrm{Fe}(\mathrm{CN})_{6}\right] 0 \cdot 2 \%$ in $2 \mathrm{M}-\mathrm{HCl}$. GC: a) Carlo Erba Fractovap 2450, FID, carrier gas $\mathrm{N}_{2}$, filled glass column $2.0 \mathrm{~mm} \times$ $\times 1.5 \mathrm{~m}, 3 \%$ OV 17 on Chromosorb G AW DMCS 80/100 mesh, injector $275^{\circ} \mathrm{C}$, programme: $\left.170^{\circ} \mathrm{C}(2 \mathrm{~min})-230^{\circ} \mathrm{C}\left(3^{\circ} \mathrm{C} / \mathrm{min}\right) ; b\right)$ Hewlett-Packard HP 5890 I, FID, carrier gas $\mathrm{H}_{2} 4 \mathrm{ml} / \mathrm{min}$ $(90 \mathrm{kPa})$, split $100 \mathrm{ml} / \mathrm{min}$, capillary column $40 \mathrm{~m} \times 0.32 \mathrm{~nm}$. OV101 crosslinked on fused silica, $0.17 \mu \mathrm{m}$, injector $245^{\circ} \mathrm{C}$, detector $250^{\circ} \mathrm{C}$, oven $170^{\circ} \mathrm{C}$. GC-MS: a) HP 5890 I, capillary column $40 \mathrm{~m} \times 0.32 \mathrm{~mm}$, OV101 crosslinked on fused silica, $0.17 \mu \mathrm{m}$, carrier $\mathrm{H}_{2}, 1.5 \mathrm{ml} / \mathrm{min}$ $\left(40 \mathrm{kPa}\right.$ ), oven temperature $170^{\circ} \mathrm{C}$ (isothermal), injector $250^{\circ} \mathrm{C}$, transfer line $170^{\circ} \mathrm{C}$, probe: $0.2 \mu 11 \%$ in $\mathrm{CH}_{2} \mathrm{Cl}_{2}$, cool on column-system, split $75 \mathrm{ml} / \mathrm{min}(1: 50)$, septum purge: $3 \mathrm{ml} / \mathrm{min}$, detector MAT $90 \mathrm{EI}-\mathrm{MS}(70 \mathrm{eV})$, delay $13.0 \mathrm{~min}$, B-scan (exp.) $35-400 \mathrm{u}$, scan rate $1 \mathrm{~s} / \mathrm{dec}$., interscan time $0 \cdot 10 \mathrm{~s}$, resolution 1130,8 samples per peak, $20.833 \mathrm{~Hz}$ sampling frequency, dynamic: $\left.2 \cdot 65.10^{6} ; b\right)$ HP MS 5970, inlet GC: $25 \mathrm{~m}$ column SE $54(5 \%)$, carrier gas He, injector $250^{\circ} \mathrm{C}$, programme: $80^{\circ} \mathrm{C}(30 \mathrm{~s})-290^{\circ} \mathrm{C}\left(10^{\circ} \mathrm{C} / \mathrm{min}\right), 290^{\circ} \mathrm{C}(2 \mathrm{~min})$, detector $\mathrm{MS}(\mathrm{EI}-70 \mathrm{eV}$, CI), TIC ( ref. $^{6}$ ).

\section{Materials}

(E)-5-Ethyl-3-nonen-2-one ${ }^{10}$ (VI). To a well stirred boiling mixture of acetone $(348.0 \mathrm{~g})$ and $10 \%$ aqueous $\mathrm{NaOH}(20 \mathrm{ml})$ 2-ethylhexanal $(207.0 \mathrm{~g})$ was added over a $16 \mathrm{~h}$ period, the last $25 \%$ being added more slowly. After complete addition heating was continued for $4 \mathrm{~h}$. Ether was added $(200 \mathrm{ml})$ and the separated aqueous layer was drained off. After washing with several portions of water, drying and stripping, the residual oil was fractionated, yielding $250 \mathrm{~g} \mathrm{VI}$, b.p. $1 \mathrm{kPa} 90^{\circ} \mathrm{C}$ (ref. ${ }^{10}$ : b.p. ${ }_{1.3 \mathrm{kPa}} 98^{\circ} \mathrm{C} ; n_{\mathrm{D}}^{16}=1.4571$ ).

5-Ethyl-2-nonanone ${ }^{11}$ (VII). Hydrogenation at $2.0-2.5 \mathrm{MPa}$ and room temperature of a magnetically stirred suspersion of $\mathrm{Pd} / \mathrm{C}(1.2 \mathrm{~g}, 5 \%)$ in $V I(120.0 \mathrm{~g})$ in an $500 \mathrm{ml}$ autoclave afforded complete reaction after $64 \mathrm{~h}$, yield $98 \%$. Several runs have been made with the recovered catalyst. The oily product was distilled over a $30 \mathrm{~cm}$ Vigreux column, b.p.1.5kPa $93^{\circ} \mathrm{C}$ or b.p.0.3kPa $67^{\circ} \mathrm{C}$ (ref. ${ }^{11}$ : b.p.o.67Pa $36^{\circ} \mathrm{C}, n_{\mathrm{D}}^{21}=1.4340$ ).

(E/Z)-5,13-Diethyl-10-methyl-9-heptadecen-8-one (VIII). In a Soxhlet apparatus the extractor thimble was filled with basic alumina (for CC. Woelm. activity $0 ; 25 \mathrm{~g}$ ) covered with glasswool. Compound VII $(100 \mathrm{~g})$ was refluxed in vacuo $(0.3 \mathrm{kPa})$ over the basic catalyst until the boiling temperature in the bottom climbed from $65^{\circ} \mathrm{C}$ to $80^{\circ} \mathrm{C}$. After about $72 \mathrm{~h}$ the reaction was stopped. The crude condensation product (bottom) ( $76 \mathrm{~g}$ ) was combined with an ether extract of the catalyst $(20 \mathrm{~g})$. After evaporation of the ether unreacted VII was removed by column distillation. (E)- and $(Z)-V I I I(2.5 \mathrm{~g})$ were separated by column chromatography on $\mathrm{SiO}_{2}(250 \mathrm{~g}$ Geduran 60 Merck 7734), with benzene-hexane (1:1) (fractions $20 \mathrm{ml}$ ). The order of elution: $(Z)-V I I I$, mixture of $(E)$ - and $(Z)-I X,(E)-V I I I$. After stripping off the solvent the pure isomers were obtained by bulb-to-bulb distillation (Büchi) yielding: $0.2 \mathrm{~g}(Z)-V I I I, 0.2 \mathrm{~g}(E)-V I I I$, and $0 \cdot 1 \mathrm{~g}(E: Z)-I X$.

5,13-Diethyl-10-methyl-8-heptadecanone (V). The crude mixture of $V I I I$ and IX $(60 \mathrm{~g})$ in $150 \mathrm{ml} \mathrm{MeOH}$ was hydrogenated on $5 \% \mathrm{Pd} / \mathrm{C}(1.0 \mathrm{~g})$ in an autoclave under magnetic stirring at room temperature and $2 \cdot 0 \cdot 10^{3} \mathrm{kPa}$. Uptake of $\mathrm{H}_{2}$ was complete after $48 \mathrm{~h}$. After removing low boiling fractions (up to $127 \mathrm{C} / 5 \mathrm{~Pa}$ ) distillation first afforded fractions up to $155^{\circ} \mathrm{C} / 5 \mathrm{~Pa}$, which still contained $V I I I$ and $I X$. The mixture was again hydrogenated in the same way. Then distillation afforded the main fraction boiling at $145^{\circ} \mathrm{C} / 5 \mathrm{~Pa}$, which consisted of rather pure $V$ $(38 \mathrm{~g})$ with less than $2 \%$ of impurities (GC).

Characteristics of the new products are given in Table $I$. 
TABLE I

Characteristics of ketones $V, V I I I$ and $I X$

$\begin{array}{ccccc} & & & \\ \text { Compound } & R_{F} & \text { IR, cm } & & \\ & n_{\mathrm{D}}^{20} & & { }^{1} \mathrm{H} \mathrm{NMR}^{a} & \text { MS } \\ & & \delta, \mathrm{ppm} & m / z(\text { rel. intensity }\end{array}$

$\begin{array}{ll}\text { (Z)-VIII } & 0 \cdot 85 \\ & 1.4680\end{array}$

$$
\begin{aligned}
& 2 \text { 961, } 2 \text { 930, 6.03 s, } 1 \text { H (H-9); } 322(62 / 100), 223(94 / 68) \text {, } \\
& 2874,2860,2 \cdot 58-2.51 \mathrm{~m}, 2 \mathrm{H} \text { (H-11); } 210 \text { (22/37), } 205(26 / 12) \text {, } \\
& 1691,16202.39-2.32 \mathrm{~m}, 2 \mathrm{H}(\mathrm{H}-7) ; \quad 195(59 / 31), 155(11 / 7) \text {, } \\
& \text { c } \quad 1.86 \mathrm{~d}, 3 \mathrm{H}\left({ }^{4} J=1 \cdot 29, \quad 152(53 / 44), 137(20 / 5)\right. \text {, } \\
& \text { C-10 Me); } 1.56-1.20 \mathrm{~m}, \quad 111(62 / 8), 98(100 / 50) \text {, } \\
& 22 \mathrm{H} ; 0.91-0.81 \mathrm{~m} \text {, } \\
& 12 \mathrm{H} \\
& 95(42 / 3), 93(84 / 15), 83 \\
& (41 /-), 81(38 /-), 69(75 /-) \text {. } \\
& 57(61 /-), 55(59 /-), 43 \\
& (59 /-), 41(47 /-)
\end{aligned}
$$

(E)-VIII $\quad 0.65$

$\begin{array}{ll}(E / Z)-I X & 0 \cdot 80 / 0 \cdot 70 \\ & 1 \cdot 4698\end{array}$

$\boldsymbol{V}$

$1 \cdot 4517$
$2961,2930, \quad 5 \cdot 30 / 5 \cdot 36 \mathrm{~m}, 1 \mathrm{H}(\mathrm{H}-11)$;

$2874,2860,3 \cdot 03 / 3 \cdot 10 \mathrm{~s}, 2 \mathrm{H}(\mathrm{H}-9)$;

$1717,1644,2 \cdot 40 / 2.40 \mathrm{~m}, 2 \mathrm{H}(\mathrm{H}-7)$; 1461

$1.95 / 2.00 \mathrm{~m}, 2 \mathrm{H} \mathrm{(H-12)}$;

$1.72 / 1.62 \mathrm{~d}, 3 \mathrm{H}$

$\left({ }^{4} \mathrm{~J}=1 \cdot 2, \mathrm{C}-10 \mathrm{Me}\right)$;

$1.57-0.7 \mathrm{~m}, 32 \mathrm{H}$
$322(8 / 11), 223(17 / 12)$,

$210(66 / 100), 195(74 / 32)$,

$155(28 / 17), 152(44 / 35)$,

$137(35 / 7), 111(52 / 13), 98$

$(100 / 61), 97(23 / 2), 95$

$(31,2), 83(30 / 1), 81$

$(25 / 2), 69(46 /-), 57(43 /-)$,

$55(43 /), 43(40 /-), 41$

$(32 /-)$

$322(8 / 31), 223(8 / 17), 210$

(9/23), $195(5 / 7), 155$

(78/48), $152(81 / 100), 137$

(100/40), 97 (15/5), 95

(52/10), 85 (14/1), 83

(17/3), $81(43 / 7), 71(24 /-)$,

$69(39 /-), 57(60 /-$,

$55(35 /-), 43(45 /-)$,

$41(28 /-)$

$324^{e}$ (7/45), $213(14 / 32)$,

197 (71/85), $171(25 / 30)$,

$155(34 / 58), 154(27 / 37)$,

153 (15/17), 152 (41/47),

$112(100 / 100), 85(85 / 47)$,

$71(61 / 8), 57(88 /-)$,

$43(52 /-)$

an $\mathrm{CDCl}_{3}$ at $90 \mathrm{MHz}$ (VIII at $250 \mathrm{MHz}$ ); ${ }^{b}$ at $70 / 12 \mathrm{eV} ;{ }^{c} \mathrm{UV}: \lambda_{\max } 239 \mathrm{~nm}(\log \varepsilon 4.49)$ in $\mathrm{CHCl}_{3} ;{ }^{d}$ IR and UV spectra identical with those of (Z)-VIII; ${ }^{e} \mathrm{HR}-\mathrm{MS}$ found: $324 \cdot 3398, \mathrm{C}_{22} \mathrm{H}_{44} \mathrm{O}$ requires $324 \cdot 3392$.

Collect. Czech. Chem. Commun. (Vol. 56) (1991) 


\section{REFERENCES}

1. Ashbrook A. W.: J. Chromatogr. 105, 151 (1975).

2. Budde W. M., Jr., Hartlage J. A.: U.S. 3637711 (1972); Chem. Abstr. 76, 99531 (1972).

3. Richards H. J., Trivedi B. C.: U.S. 4045441 (1977); Chem. Abstr. 87, 201341 g (1977).

4. Gefvert D. L., Richards H. J.: PCT Int. Appl. WO 8201369 (1982); Chem. Abstr. 97, 201231c (1982).

5. Demopoulos G. P., Distin P. A.: Hydrometallurgy 11, 389 (1983).

6. Loßmann G.: Private communication (1987).

7. Loewenberg K., Smeykal K.: U.S. 2200216 (1940); Chem. Abstr. 34, 5855 3 (1940).

8. Röhm and Haas Co.: U.S. 2148103 (1938); Chem. Zentralbl. 1939 II, 2990.

9. Seebald H. J., Schunack W.: Arch. Pharm. 305, 406 (1972).

10. Häusermann M.: Helv. Chim. Acta 34, 2172 (1951).

11. Bharucha K. R., Weedon B. C. L.: J. Chem. Soc. 1953, 1578. 